\title{
Representaciones coloniales en la escritura de Lastarria. Chile, siglo XIX
}

\author{
Colonial representations in Lastarria's writing. Chile, 19th century
}

\section{Lorena Ubilla Espinoza}

Universidad Diego Portales, Facultad de Psicología, Santiago, Chile.

Correo electrónico: lorena.ubilla@mail.udp.cl

\begin{abstract}
A partir de dos escritos histórico-literarios de José Victorino Lastarria, el presente artículo estudia la forma en que la élite chilena fue construyendo, en la primera mitad del siglo XIX, discursos sobre el pasado colonial que lo instalaban como un suceso nefasto dentro de la historia latinoamericana. Articulando metáforas que hablan de la oscuridad de este período, se nos presenta como una etapa a superar mediante la creación de una historia nacional y de un tiempo fundacional. El discurso de la emergente nación, transformado en hegemónico y oficial ya a fines de la centuria, tenía por objeto narrar y naturalizar el sentido de comunidad nacional.
\end{abstract}

Palabras clave: representaciones, tiempo histórico, Lastarria, Chile, siglo XIX

The present article discusses how the Chilean elite -represented and studied from two historical-literary writings by Jose Victorino Lastarria- built discourses on the colonial past that set it up as a disastrous event in Latin American history. Articulating metaphors that speak about the darkness of this period, the colonial period is presented as a stage to overcome by creating a national history and a foundational time. As we will see, this discourse of creating our emerging nation became hegemonic and already official by the end of the century was intended to formulate, narrate and naturalize the sense of national community.

Key words: representations, historical time, Lastarria, Chile, 19th century

\section{INTRODUCCIÓN}

El siglo XIX representó el espacio discursivo por excelencia donde el pasado colonial fue reformulado de varias maneras. Ya fuera proclamando su evasión y superación, ya fuera proclamando su aceptación y reconciliación, el pasado se vislumbró como una pérdida necesaria que permitía articular, en una nueva narración, el presente y el futuro. En este contexto, la problemática colonial pasó a jugar un rol fundamental en el pensamiento decimonónico, en la medida que permitía formular las bases de una nueva identidad cultural y nacional. 
Tomando lo anterior como punto de partida, en este artículo analizamos la escritura de Lastarria, en tanto da cuenta de una representación del tiempo colonial que disputaba su hegemonía discursiva en la construcción de un relato de nación. Para ello partimos de la premisa de que las representaciones son portadoras de lo simbólico, es decir, son construcciones sociales e históricas que una vez internalizadas en el inconsciente colectivo terminan por volverse "naturales". De ahí que el concepto de imaginario, entendido como un conjunto más o menos coherente y articulado de representaciones, nos permita evidenciar cómo su poder simbólico configura un cierto control de la vida social (Chartier 2005).

Para desarrollar el análisis utilizamos dos textos de José Victorino Lastarria: Investigaciones sobre la influencia social de la conquista $i$ del sistema colonial de los españoles en Chile (1844) y la novela Don Guillermo (1860) ${ }^{1}$. Del estudio conjunto de ambas obras se plantea que la construcción del pasado colonial como un período nefasto en nuestra historia latinoamericana, surgió para homogeneizar la heterogeneidad propia del "bajo pueblo" en la época colonial (pensemos en las repúblicas de indios, en los mestizos, o en los cuadros de castas destinados a "ordenar" el "desorden" étnico y social). De ahí la necesidad de persuadir al lector, que es a la vez el ciudadano, de que dicha heterogeneidad podría evitarse mediante la construcción de una historia nacional que sirviera para civilizar a quienes poco contribuirían a forjar el progreso nacional. Claramente, en este mismo sentido, creemos que se inscriben las llamadas campañas de "pacificación de indígenas" que asolaron nuestro continente a fines del siglo XIX, y que en Chile derivaron en la incorporación del pueblo mapuche al territorio nacional, negando sus tradiciones, historia e identidad.

El ensayo histórico, debido a su condición de espacio escritural flexible -podía ser una carta, una confesión, una conferencia o un artículo científico o periodístico-, permitió a los escritores decimonónicos articular una red discursiva que buscaba inducir una experiencia en el pensamiento del lector. De ahí que no sólo destaque por su carácter retórico, sino sobre todo (y es principalmente la función que nos interesa destacar en la propuesta de lectura de Lastarria) por su faceta persuasiva.

Desde esta mirada analizamos en particular el ensayo Investigaciones sobre la influencia social de la conquista i del sistema colonial de los españoles en Chile, pues en él el autor estudia cómo la influencia del pasado colonial ha detenido el progreso de la República, y ha mantenido al país en un "manto de tinieblas". A la vez, nos interesa complementar el análisis con la novela Don Guillermo, pues en ella encontramos conviviendo, por un parte, los males que ha causado la dominación española en las vidas cotidianas de las personas, y por otra, la idea de que las limitaciones personales y sociales se superan sólo a partir de abrazar los ideales de progreso propios de la modernidad europea ilustrada. Finalmente, creemos que el estudio de ambos géneros literarios enriquece la lectura, en cuanto el ensayo histórico nos muestra con "documentos auténticos" y con una narración "imparcial" (Lastarria 1906: 18) las propuestas y proyectos para la formación de esta nueva identidad

Don Guillermo se centra en el viaje que realiza su protagonista al mundo subterráneo de Espelunco (anagrama de pelucones). Este mundo es una representación alegórica de la época colonial y de los "gobiernos pelucones", llamados con este nombre porque sus miembros utilizaban pelucas en imitación a la cámara de los Lores inglesa. Brevemente, cabe anotar que los gobiernos "pelucones" corresponden a los tres decenios de gobiernos conservadores, que se extienden de 1831 a 1861, y cuyos emblemas son la figura política de Diego Portales y la constitución autoritaria de 1833. Recién en 1861, es decir, un año después de publicada la novela Don Guillermo, los liberales pudieron acceder al gobierno bajo la presidencia de José Joaquín Pérez. 
nacional, mientras que el registro literario nos acerca a los sentimientos, las pasiones y las frustraciones de los personajes por lograr este cometido.

Desarrollamos tres ejes temáticos en los cuales el corpus textual ocupa un lugar central: en una primera parte estudiamos la visión que tiene Lastarria del período colonial, visión que se encuentra determinada por su entendimiento de la historia basada en una concepción de tipo liberal; en el segundo apartado veremos cómo el autor construye un relato de temporalidad colonial que se opone a los aspectos que valora y releva como necesarios para la construcción de una temporalidad nacional. Y, por último, estudiamos cómo su escritura selecciona y adapta los discursos europeos que circulaban en aquella época, como parte de pensar y encajar nuestras historias latinoamericanas a la anhelada senda de la civilización y el progreso.

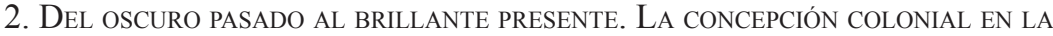 ESCRITURA DE LASTARRIA}

José Victorino Lastarria se inserta en un contexto latinoamericano en el cual el pensamiento liberal era la base de las teorías y los programas tendientes a la (re) organización de las sociedades que acababan de independizarse, y a la consolidación de los gobiernos nacionales. Sin duda, la adopción del discurso liberal en América Latina chocaba con la historia y la realidad de nuestros países, muy estratificados socialmente y subordinados al contexto económico internacional.

Así, la primera mitad del siglo XIX nos muestra conflictos, tensiones y disputas por instalar una interpretación y evaluación de lo que implicó la influencia del pasado colonial en el continente ${ }^{2}$. Sin embargo, ya a fines de este siglo resultaba evidente que en esta disputa se había instalado un discurso hegemónico amparado en el liberalismo, que consolidaba un "mito unificador" y que chocaba con el orden colonial heredado. De ahí que en comparación con la primera mitad del siglo XIX, los años finales de esta centuria se nos presenten como "años de consenso político" respecto al entendimiento de la época colonial (Hale 1990).

Pero volvamos a ese terreno de disputa, pues es en este contexto donde los escritos de Lastarria adquieren significación. Como parte del programa de fundación de una literatura nacional, en 1842 Lastarria lee un discurso en la naciente Sociedad Literaria, en el que expone tanto un programa literario como una concepción historiográfica. En dicho discurso reafirma la utilidad (o misión) histórica de la literatura, es decir, ponerse al servicio de la transformación de la mentalidad colonial en conciencia nacional ${ }^{3}$.

En este sentido podemos comprender la polémica entre Andrés Bello y Lastarria respecto a la interpretación del pasado colonial. Si para Lastarria era fundamental la ruptura total con todo lo que fuera el legado español, en Bello se rescata esta herencia española precisamente porque fue la que le permitió a los latinoamericanos insertarse en el mundo de la civilización. Para una comprensión de esta diferencia, ver Meléndez (1998).

3 Bernardo Subercaseaux nos advierte que en los años en que se funda la Sociedad Literaria no había una diferenciación tajante entre historia y literatura, y de hecho, las ideas historiográficas tenían mayor importancia que las cuestiones estético-literarias. "Existía, por lo tanto, una zona intermedia que les era común: el rescate del pasado y la función edificante. En estas circunstancias era explicable que se produjesen préstamos, coincidencias y zonas híbridas de difícil delimitación" (1997: 80). Asimismo, y siguiendo a Gonzalo Catalán (1985), si hay algo que define al intelectual decimonónico durante este período es la síntesis que en él se realiza, primero, entre las funciones de liderazgo político y, segundo, entre las diversas expresiones y géneros que cultiva indistintamente: puede ser poeta, diarista, orador, novelista, crítico, historiador, jurista o cronista. Esta ausencia de diferenciación y especialización de los géneros lleva a que el autor plantee que no existe autonomía del campo literario durante gran parte del siglo XIX, configurándose recién en la última década de este siglo. 
Para Lastarria esta función edificante de la literatura guarda relación con una comprensión de la realidad histórica que atraviesa las dos obras estudiadas. La Historia es concebida en términos de desarrollo y vinculada a conceptos de progreso y perfectibilidad social. Es una evolución que presupone una cierta dirección y que está determinada por la presencia de leyes invariables e inmutables que llevarán a la sociedad a su progreso material y espiritual. Desde esta perspectiva, el progreso de la humanidad no se considera como un producto histórico, sino como un fenómeno inherente a la naturaleza del hombre. Esta concepción de la Historia resulta fundamental al momento de comprender su evaluación respecto del pasado colonial. En efecto, al concebir la historia humana bajo los parámetros que rigen al mundo natural, Lastarria concluye que la colonización española fue una empresa contra la naturaleza, en cuanto frenó la marcha de progreso, de ahí que la independencia sea vista, por una parte, como el momento en que la historia (ultrajada) empieza a recobrar su dignidad y, por otra, como el momento en que el hombre puede acceder a la razón que le fue vedada (ultrajando su propia naturaleza interior) por la dominación que sufrió.

Claramente, este entendimiento del período colonial da cuenta de una adopción de los discursos cientificistas que circulaban por entonces en Europa, y de la necesidad del autor por ajustar la comprensión del período colonial a las leyes históricas en boga. Lo anterior lo podemos apreciar cuando realiza el contraste entre el pasado colonial y su presente, marcado por la realidad post-independentista:

\footnotetext{
La ignorancia i la esclavitud forman su existencia durante tres siglos, i se esfuerzan por mantenerlo perpetuamente bajo su funesta cautela, inspirándoles preocupaciones i costumbres antisociales que lo preparan desde su infancia a una eterna degradación. La naturaleza, empero, que no puede soportar por largo tiempo los ultrajes de los hombres, recobra al fin su imperio, hace triunfar la divinidad envilecida i da principio a una era de gloria i de ventura: el pueblo humillado por la esclavitud i la ignorancia, vindica sus hollados fueros i se presenta hoi en carrera para un porvenir brillante (Lastarria 1906: 32).
}

Como vemos, la comprensión de la época colonial como una etapa de envilecimiento de la naturaleza humana, en la que el ser social pierde su libertad y perfección, es una idea fuertemente remarcada. Desde esta mirada, la influencia de la conquista resultaba altamente negativa y venía a confirmar, en todos sus aspectos, la leyenda negra de España. El hecho de que Lastarria considerara que los principios que activaron la revolución de la independencia se encontraban inconclusos, se debía a que el espíritu colonial seguía ligado a la administración de los "gobiernos pelucones", de ahí que resultara necesario derrocar este legado y "demoler el pasado para reconstruir nuestra civilización" (Lastarria 1906: 4-5).

Las imágenes metaforizadas construidas sobre el pasado colonial son completamente opuestas a las que emergen con la independencia, y guardan relación con la asociación a fenómenos naturales nocturnos y sombríos. Al respecto, Lastarria plantea que la historia de nuestro pueblo consta de "tres siglos de una existencia sombría i sin en las tinieblas de los tiempos" (Lastarria 1906: 32). Otra de las metáforas asocia al hombre colonial con la esclavitud e ignorancia: "La ciega sumisión (...) la dura esclavitud de un humillante vasallaje (...) y el terror de un poder doméstico que 
sojuzgaba hasta las conciencias casi lograron apagar y extinguir en el alma del ser humano, los gérmenes de todo sentimiento social y de toda aspiración brillante: era un pueblo dormido"4 (Lastarria 1906: 30).

Podemos apreciar que para Lastarria resultaba esencial construir e instalar un discurso que enfatizaba las diferencias entre un tiempo colonial y otro nacido con la emancipación. De ahí que él mismo considerara que quienes tenían reticencias a la Independencia, no habían logrado sacudirse de la esclavitud que en sus conciencias había marcado la dominación española. Sin embargo, y siguiendo las mismas leyes inmutables de la historia, era impensable que sus consciencias siguiesen por siempre aletargadas, ya que el despertar de la "naturaleza humana jamás [se] extingue, aunque [se] apague por largo tiempo el poder de desarrollo intelectual y moral que es congénito e inherente al hombre" (Lastarria 1906: 30). Nuevamente, es posible apreciar aquí la fe evolucionista en el desarrollo histórico, y el muy liberal entendimiento de que la esencia de la naturaleza humana conducirá a los hombres en la senda del progreso.

Ciertamente, la intencionalidad política del discurso histórico-literario de Lastarria opera en términos de contraste para reafirmar y relevar la operación discursiva de la homogeneización liberal, en la que el Estado republicano emergía como el instrumento edificador del nuevo, y necesario, sentir nacional.

\section{LASTARRIA COMO SUJETO MODERNO: LA CONSTRUCCIÓN DE TEMPORALIDADES HISTÓRICAS}

La primera modernidad europea, entendida como un constructo nacido de la interrelación con el continente americano, implicó la elaboración de relaciones intersubjetivas y de perspectivas de conocimiento que fueron progresivamente resignificadas, releídas y reelaboradas a la luz de una segunda modernidad, en la cual el sistema de conocimiento anterior, fundado en la idea de 'semejanza', fue dando paso al sistema de explicación de la 'diferencia' en el origen y el desarrollo de las sociedades. En esta nueva perspectiva temporal de la historia fueron reubicados los pueblos colonizados y sus respectivas culturas, instalando categorías como la infancia de América, lo errático de sus proyectos, o la inmadurez en su desarrollo. Al mismo tiempo, desde aquí se explicaba que la superioridad de Europa no formaba parte de su dominación, sino del estado "natural" de civilización alcanzado por ella, el cual debía ser objeto de imitación.

En la formulación de esta matriz de pensamiento, la imagen del otro resultaba esencial. Según Jorge Larraín (1996), esta noción de el/lo otro diferente opera en

Estas ideas, expresadas explícitamente en el ensayo Investigaciones ..., resulta interesante leerlas metaforizadas en el "ensayo de novela histórica", El Mendigo (1843), que cuenta la vida de Álvaro, un criollo y antiguo soldado de la patria que termina convertido en pordiosero. Mediante su vida se critican los vicios propios de una "mentalidad colonial", a pesar de que haya destacado en la lucha por la independencia. En términos cronológicos, la narración abarca desde los últimos años de la Colonia hasta los años que siguen a la Reconquista Española. Aquí los personajes, ambientes y circunstancias se encuentran marcados, en su propia vida cotidiana, por un presente de plenitud asociado al contexto histórico independentista -en el cual se instala el narrador-. Esta situación marca el contraste con el pasado colonial ejemplificado en Álvaro, cuyas desgracias son producto, todas y sin excepción, de personajes españoles: un militar español se apodera del dinero de su amigo Alonso; la segunda separación de su amada Lucía, fuente de sus posteriores desventuras, es provocada por el tiránico español Don Gumersindo (caracterizado como agresivo, ocioso y dueño de esclavos); la deshonra de Lucía es consumada por Laurencio, también militar español y es, finalmente, uno de los oficiales realistas de la batalla de Rancagua, el coronel Lizones, quien imposibilita la unión de ambos, llevándose a Lucía primero a Lima y luego a España. La obra está disponible en: http://www. memoriachilena.cl/archivos2/pdfs/MC0001080.pdf 
tres planos: una primera dimensión temporal, cuyo eje es la ruptura con un pasado que se considera obsoleto y que permite construir un nuevo relato sobre el presente y el futuro; una segunda dimensión social, que pone al otro como aquel sujeto que no cumple con algún requisito considerado y codificado como significativo en la sociedad (el caso de los trabajadores en un primer momento, las mujeres, o los locos), y; finalmente, una dimensión espacial, según la cual el otro es aquél que vive fuera, es decir, el bárbaro o primitivo que no ha sido aún civilizado.

Desde este horizonte de comprensión, en este apartado analizamos cómo nuestro autor construye una temporalidad colonial asociada a lo obsoleto, primitivo y bárbaro, contraponiéndola con una "temporalidad fundacional" (Subercaseaux 1997) basada en la homogeneidad y en el orden como aspectos fundamentales para legitimar el discurso de la emergente nación ${ }^{5}$.

En ese sentido, el establecimiento de una frontera temporal -entendida como un "ayer" que debe ser superado por un "hoy"-, puede enmarcarse en la subjetividad propia nacida con la modernidad. Con ello nos referimos a que la escritura de Lastarria evidencia la centralidad que adquiere la conformación del sujeto moderno. Es por ello que, permanentemente, llama a sus lectores a romper las cadenas que ha dejado en sus conciencias la colonización, instándolos a proclamar como suyos los ideales de progreso, liberalismo y cientificismo -o, como diríamos hoy, más bien positivismo-.

Al respecto puede resultar aclarador el análisis de La Odisea planteado por Horkheimer y Adorno en Dialéctica de la Ilustración (1998), para comprender tanto el proceso de formación de la subjetividad moderna, como la ruptura con el pasado colonial que realiza Lastarria en sus escritos. Como sabemos, en La Odisea se nos presenta la figura del viaje como parte fundamental del itinerario de la experiencia formativa de la propia conciencia. En este viaje, el protagonista, Ulises, se expone a tentaciones que lo distraen de la formación de sí mismo, ante lo cual entiende que sólo la auto-comprensión de sus sentimientos (es decir, la "domesticación" de su naturaleza interior) lo ayudará a superarlas. De ahí que resulte central, en su construcción como sujeto, el establecimiento del imperio de la razón por sobre sus emociones. En ese contexto, entonces, la experiencia de encontrarse con "otros" (la diversidad) es vivida sólo en cuanto confirma la unidad de sí mismo. En otras palabras, si la experiencia de la diversidad ("lo otro") impulsa a la disgregación mediante la ambivalencia, el único instrumento que puede superarla es la razón (comprensión de "lo propio").

Volviendo a Lastarria, en la novela Don Guillermo nos encontramos con esta experiencia formadora del viaje, en este caso el mundo subterráneo de Espelunco (anagrama de pelucones). Aquí, el tiempo, el espacio y los lugares forman el canal que nos inserta en un mundo simbólico y alegórico, en el cual Mr. Livingston va comprendiéndose y formándose a sí mismo como un sujeto racional, cuya misión es volver al mundo de arriba y establecer el orden de los principios liberales. En dicho viaje, el protagonista se enfrenta con diversos personajes que representarían la disgregación, el desorden y el descontrol, frente a los cuales debe utilizar la razón para salir airoso. De hecho, no deja de llamar la atención que sea Lucero, el hada del

Para este análisis hemos utilizado la propuesta de Foucault (1999) que entiende el discurso en un sentido amplio, esto es, como prácticas sociales que se expresan tanto en actos de habla, como en múltiples soportes y lenguajes, refutando la concepción de acción y discurso como categorías opuestas de análisis. 
patriotismo, quien lo ayude a salir de este reino de tinieblas y oscuridad. Es necesario destacar que este mundo subterráneo, símbolo de la permanencia del legado colonial, está ubicado justamente bajo tierra, precisamente donde no llega la luz que pueda despertar al hombre de esta oscuridad (metáfora de la naturaleza humana).

La salida de Mr. Livingston de Espelunco ratifica no sólo que sus convicciones personales/liberales han sido afirmadas, sino más aún, que éstas pueden reformar el mundo de arriba. De ahí que su peregrinaje entre Santiago y Valparaíso (debe completar tres mil viajes entre ambas ciudades repitiendo las palabras "justicia, patriotismo y democracia"), represente la manifestación concreta de la formación de su propia conciencia. Sin embargo, el hecho de que finalmente fracase en su cometido y muera atropellado, se explicaría porque en el mundo de arriba, aún gobernado por los conservadores, no se ha producido un cambio total en las conciencias de los individuos.

Entonces, si asumimos que Lastarria es un sujeto plenamente moderno, comprenderemos su afán por instalar un discurso que opone la temporalidad colonial a la temporalidad fundacional. En esta trama de representaciones confluyen la acción y el efecto de escenificar el tiempo, estableciendo relaciones de anterioridad (un "ayer" entendido como el pasado colonial que hay que superar), relaciones de simultaneidad (un "hoy" marcado por la presencia del discurso liberal), y relaciones de posterioridad (un "mañana" sin resabios del tiempo colonial). Desde estas coordenadas se establece la matriz discursiva que tiene como agente a toda la élite ilustrada, quienes, apoyados en la prensa, el sistema educativo, el derecho, los ritos, las conmemoraciones cívicas o la propia literatura e historiografía, transmitieron un sentido de nación acorde a su visión y por sobre las tradiciones culturales y de referencia de los "otros" habitantes.

En la construcción de esta nueva temporalidad se apela a las metáforas que vimos con anterioridad, y a aquellos elementos considerados perjudiciales en la evolución y el progreso de la sociedad, como son el conservadurismo, la religión y la monarquía. De hecho, en Don Guillermo nos encontramos con cuatro poderosos "monstruos" que no son más que ideas-fuerza que resumen el pasado colonial. He aquí un pasaje que ilustra el juicio que se le hace en Espelunco a Mr. Livingston por no renegar de sus ideas liberales. En dicho juicio, el juez lo considera culpable y lo tilda de:

loco (...) trastornado por las ideas revolucionarias, y que pretende reformar el mundo, haciéndole olvidar la religión y renegar de la obediencia pasiva a sus tutores naturales, sin cuyos bienes no hay orden ni sociedad posibles. Contra esos locos obra nuestro poder (...) en la esperanza de que no cundan las ideas nuevas y de que se rehabiliten con todo su esplendor en América el espíritu y las costumbres de los afortunados tiempos de la Colonia. Milagrosamente tenemos a ardientes servidores en el país (...) que son los cuatro poderosos monstruos (...) la Mentira, la Ignorancia, el Fanatismo y la Ambición (Lastarria 1973: 68).

En Espelunco no existe el tiempo, existe más bien una atemporalidad que obedecería a un tratamiento alegórico, a un correlato del tiempo colonial. Se trata de un tiempo sin evolución histórica alguna, estacionario y fijo, donde todo se estanca y nada avanza, es decir, donde no hay progreso. En cambio, en la construcción de la temporalidad fundacional el tiempo avanza en la medida que la sociedad en su conjunto progresa, de ahí que sirva para dotar un relato de la comunidad nacional. 
Como es ampliamente sabido, la nación no está constituida sólo por el territorio, la población o el gobierno, sino que por la capacidad constante de articular y crear sentidos y sistemas simbólicos capaces de generar lealtades, vínculos, entusiasmos o rechazos colectivos. Toda nación necesita, por tanto, de un proyecto de futuro y un sentido de trascendencia, es decir, de un "mito" o un "cuento" que articule, dé sentido y opere (finalmente que se naturalice) en un relato (coherente o no) de la historia de una comunidad (Anderson 2000). De esta forma, en la escritura de Lastarria, la ruptura con el tiempo colonial resulta fundamental para articular el nacimiento del relato y de la temporalidad nacional. Es una elaboración simbólica en la cual el diseño del tiempo histórico desempeña un rol fundamental, de progreso. Esta construcción discursiva, que resulta tanto de componentes racionales (elaboración intelectual de un sentido de la historia o apropiación y disputa por imaginarios hegemónicos), como no racionales de la vida social (sentimientos de pertenencia, de comunidad o imaginarios colectivos compartidos), cruza su escritura otorgándole una funcionalidad y un carácter persuasivo a su obra.

Si el pasado nos remite a la temporalidad (atemporal) colonial y el presente a la temporalidad fundacional, el futuro del espacio discursivo es el de la temporalidad nacional. En este sentido, evidentemente, Lastarria está pensando en una nación de ciudadanos, en una nación de sujetos modernos que estén unidos por un conjunto de creencias, valores y tradiciones, es decir, que estén unidos por una sola cultura nacional. Para él, como para gran parte de élite decimonónica, los particularismos, las diferencias culturales y "los otros" distintos a su clase e intereses (primero los indígenas y el bajo pueblo, luego los "rotos alzados" de fines del siglo XIX, y más tarde los "obreros sin patria" del siglo XX), fueron vistos como un obstáculo para la construcción de repúblicas ordenadas y civilizadas.

En ese contexto, se comprende la derrota definitiva de Mr. Livingstone: a mediados del siglo XIX la construcción de una temporalidad nacional aún no era factible. La influencia que seguía ejerciendo el pasado colonial se manifestaba todavía en la falta de una subjetividad moderna que fuera capaz de "emancipar" las conciencias y "avanzar" hacia un futuro, donde la falta de civilización y progreso fueran sólo malos recuerdos de un tiempo superado. En palabras de Lastarria:

El héroe [refiriéndose a Mr. Livingston] había vencido a la Ignorancia y a la Mentira con una firmeza incontrastable, y se había salvado del poder de la Ambición y del Fanatismo con un valor de todos los diablos. ¡Trabajo perdido! Su admirable constancia no alcanzó a desencantar al Patriotismo, y la Verdad, la Justicia y la Democracia quedarán todavía en los abismos, hasta que las levante de allí otro héroe que no muere jamás (...) otro héroe (...) a quien los griegos llamaban Demos (...) y a quien nosotros llamamos Pueblo, en nuestro lenguaje moderno (Lastarria 1973: 152).

\section{LA MODERNIDAD LATINOAMERICANA: UNA VISIÓN DESDE EL SUR}

Pensar la modernidad en América Latina suele conducirnos a comparaciones con el modelo europeo desde el cual emerge la conclusión de la dependencia y subdesarrollo de nuestros países. Conclusión innegable desde esta perspectiva, pero que, sin embargo, evidencia un desconocimiento de la propia realidad particular en la construcción de nuestras sociedades. Podríamos decir que desde que las sociedades 
latinoamericanas alcanzan una relativa independencia, tanto en términos políticos como sociales, o sea, con la conformación de estructuras capaces de pensarse y actuar desde sus propias realidades, la modernidad deja de ser un problema ajeno y de otros, y pasa a ser un problema cercano y nuestro.

Primero, y en términos políticos, la modernización se presentó como una demanda nacida de una minoría elitista que quería liberarse de la dominación peninsular al alero de las ideas de la Ilustración y que, en el transcurso del siglo XIX, logró construir y configurar el Estado nación moderno y liberal. Segundo, y en términos económicos, esta modernización se evidenció en la inserción de Latinoamérica como productor y abastecedor de materias primas al mercado internacional capitalista, en una relación marcada por la desigualdad y la dependencia. Ello, porque los capitales y las iniciativas empresariales fueron monopolio de las compañías extranjeras, y el rol de las élites locales no pasó de ser subsidiario.

Desde esta perspectiva, apreciamos que lo común a ambos casos fue un proceso de entrada a la modernidad conducido "desde arriba", con una integración parcial o casi nula de otros actores sociales, y marcada por una mirada disciplinadora hacia quienes se negaban a formar parte de este proceso (un caso ejemplar en este sentido es la experiencia del pueblo mapuche hacia fines del siglo XIX, tanto en Chile como en Argentina).

Esta entrada elitista a la modernidad respondía a la conciencia que como grupo estaban adquiriendo de vivir en una época que -de acuerdo a lo que hemos visto en los escritos de Lastarria- era considerada "nueva" en relación con un pasado colonial, tradicional e inmóvil. La modernidad, desde sus ojos, estaba asociada a un sentimiento de superioridad, tanto respecto del pasado como de los otros sujetos que no la experimentaban.

En este contexto de producción intelectual se inserta la escritura de Lastarria. Como la mayoría de los intelectuales que proclamaron la Independencia de Hispanoamérica, el autor formula interpretaciones que considera orgullosamente americanistas. Sin embargo, estas interpretaciones, en realidad, más "que europeas, eran europeizantes". Bajo esta distinción, Pratt (1997) resume la apropiación transatlántica a través de la cual la intelectualidad liberal empezó a buscar los fundamentos estéticos e ideológicos en cuanto (hombres) americanos. Dichos fundamentos, en gran medida, fueron encontrados en el liberalismo. Sin embargo, la ideología liberal en América tuvo un sentido claramente distinto del europeo.

En primer lugar, porque el liberalismo europeo fue una corriente llevada a cabo para la consolidación y el fortalecimiento de una burguesía diferenciada profundamente del grupo aristócrata. En cambio, en la América Latina decimonónica, al no existir una burguesía consolidada e independiente en cuanto a su constitución de clase, el liberalismo fue adoptado, precisamente, por los sectores de la "aristocracia". En segundo lugar, porque esta élite presentaba un pasado colonial criticado pero que, paradójicamente, también formaba parte del "aparato" mental con el cual seguía profundamente ligada, lo cual explica que muchas de sus contradicciones internas hayan terminado generando una tensión permanente entre los elementos coloniales y los anhelos de una modernidad avalada por las premisas de libertad y progreso. En ese contexto restringido, la apropiación política e ideológica del liberalismo era vista como necesaria para la fundación de una sociedad y una cultura americana descolonizada e independiente, aunque basada en los valores europeos apreciados en la época. 
No cabe duda de que la élite que llevó a cabo la Independencia se enfrentó con el gran desafío de tener que construir y dar sentido a un proceso que le era desconocido. Por ello, podemos explicarnos tanto la necesidad por construir discursos e imaginarios sobre el pasado colonial, como las contradicciones ejemplificadas en la ruptura colonial con España, y en la nueva dependencia (neocolonial) establecida con Inglaterra en lo económico, y con Francia en lo cultural.

Claramente, en el contexto de fundar e imaginar la nación, la escritura adquiría un papel fundamental. Efectivamente, el registro escritural -ya fuera político, histórico, literario, o simplemente los tres, pues recordemos que en esta época no existen campos plenamente diferenciados de producción de conocimiento- le permitió a estos intelectuales dar cuenta de las tensiones y los conflictos que iban sufriendo en el proceso de construir el relato histórico de la nación. Es por ello que esta creación y formulación era vista por Lastarria como esencial, en la medida que permitía otorgar sentido a una nueva temporalidad amparada en criterios de "objetividad". Al respecto, resulta aclarador lo que declara en su texto Investigaciones... (1844), cuando le expresa al lector las motivaciones que lo llevaron a estudiar el período colonial:

He encaminado todos mis esfuerzos a caracterizar la conquista i su inmediato resultado, es decir, el establecimiento del sistema colonial español entre nosotros, para poder apreciar sus influencias en esta sociedad (...) Confieso, señores, que yo habría preferido haceros la descripción de alguno de aquellos sucesos heroicos o episodios brillantes que nos refiere nuestra historia, para mover vuestros corazones con el entusiasmo de la gloria o de la admiración [pero] desarrollándose todavía nuestra revolución, no estamos en el caso de hacer su historia filosófica, sino en el de discutir i acumular datos, para transmitirlos con nuestra opinión i con el resultado de nuestros estudios críticos a otra jeneración que poseerá el verdadero criterio histórico i la necesaria imparcialidad para apreciarlos (Lastarria 1906: 30-31).

Es, precisamente, en el hecho de asumir el desafío que implicaba dar sentido a esta nueva realidad, donde Lastarria ubica la importancia de lo sucedido en "la revolución de la Independencia". Esta ruptura con el nexo colonial era percibida por él, como por gran parte de la intelectualidad latinoamericana de la época, como el suceso que los llevó a embarcarse en un futuro que trascendía la experiencia de las sociedades europeas. En sus palabras: "Yo creía entonces, como ahora, lo que no he venido a leer en autores europeos sino en estos últimos años, que era necesario rehacer la (...) historia, porque no basta estudiar los acontecimientos, sino que es indispensable [haber vivido] la esperiencia de sus antepasados" (Lastarria 1906: 31).

Es interesante que, bajo esta mirada, América aparezca otra vez como un "Nuevo Mundo", como un espacio en el cual había lugar para la experimentación de las ideas que en Europa estaban en boga. Ello porque las élites se veían forzadas a "imaginar" en la práctica muchas cosas que no existían, incluyendo la propia construcción de una nación en la cual ellos mismos se verían subordinados a los ideales republicanos. Como sabemos, en última instancia, la formulación de esta aspiración intelectual (la independencia latinoamericana) fue usualmente expresada en términos alegóricos abstractos que no hacían más que tensionar las contradicciones existentes, en el intento de legitimar sociedades jerárquicas a través de ideologías igualitarias ${ }^{6}$.

Las dificultades de los sectores dominantes para conciliar los nuevos valores liberales de igualdad, ciudadanía y 
Al respecto, la lectura de Don Guillermo resulta nuevamente aclaradora. Durante su viaje, Mr. Livingston va tomando conciencia de la necesaria implantación de los valores liberales en un mundo que continúa plagado del legado de las tradiciones coloniales. En el intento por confrontar la "herencia oscura" del pasado aparecen los cuatro "monstruos" coloniales, o sea, la barbarie alegorizada, que impide que se realicen estos ideales?. Desde aquí leemos que la apelación a estos "monstruos" era esencial en la construcción del tiempo nacional, en cuanto legitimaba un discurso hegemónico que arrasaba con la diversidad cultural asociada a la temporalidad colonial.

La escritura de Lastarria muestra cómo se fueron adoptando discursos europeos que, de una parte, buscaban romper con el pasado colonial, pero de otra, lo hacían bajo una matriz de conocimiento que legitimaba la producción europea. En ese sentido, creemos que en el entendimiento de la irresolución de tantas de estas contradicciones (afirmación de valores igualitarios, democráticos y anticoloniales que en la práctica no fueron realizados), el análisis del espacio literario es útil pues entrega algunas pistas que explican por qué las ideas-fuerza liberales aparecen aquí transformadas en personajes alegóricos, como héroes y hadas, que finalmente no logran cumplir con su cometido. Igualmente, aquí apreciamos que es una sociedad entera la que está en proceso de (re)construcción, y cuyos nodos conflictivos están siendo atravesados por la construcción del Estado y la nación, así como por la implementación temprana del proceso de modernización capitalista.

Podemos afirmar que José Victorino Lastarria, como gran parte de la intelectualidad liberal latinoamericana del siglo XIX, es un sujeto atravesado por una episteme eurocéntrica que no sólo rompe con el pasado colonial, sino que se apropia del discurso cientificista del progreso, con el fin de imaginar una sociedad bajo los ideales de la modernidad europea. No obstante, el lector podrá conceder que lo interesante de su estudio radica, justamente, en el intento de comprender sus escritos como parte de las producciones intelectuales que sirvieron, en su momento, para construir, legitimar y naturalizar la historia de nuestra naciente comunidad nacional.

Porque, y como sabemos, pese a estas contradicciones y tensiones iniciales, el proyecto liberal-republicano terminó siendo adaptado y reivindicado por el conjunto de la sociedad. Querámoslo o no, la percepción de la nación, o el sentido de comunidad, "se construye desde esa constelación de ideas legitimadas de referencia universal y abstracta, aunque en los hechos, no se pongan en práctica o se las ponga en práctica de un modo limitado y excluyente" (Subercaseaux 2003: 52).

Dejando de lado toda discusión respecto a si somos modernos o no, y admitiendo que la ruptura colonial fue más bien nominal que de facto, creemos necesario afirmar que, si bien aquí se actualizan y verifican muchas de las contradicciones nacidas en el contexto de origen de la modernidad, del mismo modo ésta adquiere nuevas (re) significaciones y (re)apropiaciones al amparo de nuestras particularidades históricas.

nación, con la notable jerarquización de la sociedad del Chile post-Independencia, son analizadas en: Pinto, Julio y Verónica Valdivia. 2009. ¿Chilenos todos? La construcción social de la nación (1810-1840). Santiago: LOM.

Es interesante notar aquí que la barbarie no es un "otro", sino un "nosotros mismos" en un tiempo pretérito. Posteriormente, los valores y conductas "bárbaras" van a dirigirse hacia el bajo pueblo y sus manifestaciones pertenecientes a un pasado desdeñable. En un primer momento, la religiosidad y los carnavales populares van a ser fuertemente criticados. En cambio, el transcurso del siglo, los bajos niveles de civilidad y las conductas inorgánicas y disruptivas van a ser el centro de la crítica elitista. 
Como lo expresa Larraín, no se trata de ver nuestra modernidad como un fracaso marcado por la experiencia del subdesarrollo o la dependencia, ni tampoco de entendernos como una mala copia del modelo ilustrado nacido en Europa. Más bien, se trata de comprender que:

\begin{abstract}
Nuestra modernidad no es la misma modernidad europea; es una mezcla, es híbrida, tiene problemas serios; es en suma una modernidad precaria, subordinada y periférica, ni puramente endógena, ni puramente impuesta (...) De esta manera, la especificidad o "modo periférico" de la modernidad latinoamericana se manifiesta claramente en la heterogeneidad de los procesos de modernización que afectan diversas áreas de la cultura y la economía (Larraín 1996: 234-235).
\end{abstract}

Desde esta perspectiva -y esta vez reflexionando sobre las celebraciones de los Bicentenarios-, pareciera fundamental (re)pensar críticamente las matrices bajo las cuales aprehendemos la construcción de "lo latinoamericano". Ello porque la producción de conocimiento realizada desde una visión eurocéntrica relega a un segundo plano las manifestaciones y expresiones que circulan en nuestro espacio, asociándolas con imitaciones pobres, atrasadas y burdas de lo realizado en los llamados "focos de civilización". Es por esto que decidimos analizar este tiempo de tensiones y conflictos como una época que discute la ruptura de/con lo colonial. Pues, en última instancia, creemos que las disputas en torno a la evaluación del pasado evidencian que fue un período que permeó y configuró una forma distinta de entrar a la modernidad.

\title{
5. REFLEXIONES FINALES
}

En este artículo nos hemos acercado a la construcción de un discurso sobre el pasado colonial que tenía como fin, por una parte, persuadir y enseñar a los (hombres) ciudadanos cómo se debía dirigir la organización de la naciente República y, por otra, construir un imaginario de las temporalidades históricas que explicara, diera sentido y legitimara la realidad post-independencia. Desde ese foco estudiamos por qué el tiempo pasado fue tan criticado, no sólo en la escritura de Lastarria, sino también en una parte importante de la élite criolla. De hecho, la construcción de metáforas e imágenes bajo las cuales se visualizó el período (oscuridad, tinieblas, ignorancia, esclavitud, despotismo), da cuenta de la importancia y la legitimidad que alcanza el discurso de identidad cultural-nacional.

$\mathrm{Al}$ respecto, resulta interesante reflexionar sobre la fuerza que actualmente siguen teniendo estas imágenes. Por ejemplo, un caso relevante es el escaso tratamiento que en los manuales escolares se dedica al pasado colonial, entendiéndolo como una época homogénea, sin rupturas y estática -pensemos en el tiempo sin tiempo de Espelunco-, y centrada en el estudio de las instituciones. Por el contrario, el proceso independentista es visualizado como un despertar y como el inicio de un período donde el país se inserta progresivamente en el carril de la historia y del progreso. En ese contexto, fue precisamente la fuerza de estas representaciones la que me movió a pensar en la efectividad de la construcción de esta temporalidad nacional, y en la necesidad de reflexionar por qué y cómo llega a instalarse este discurso sobre el pasado colonial como hegemónico. 
Tomando como punto de partida y de llegada la idea de la colonialidad ${ }^{8}$, podríamos replantearnos críticamente esta visión que sigue formando parte de nuestro imaginario y sentido común cotidiano - pensamos, ahora, en la falta de políticas públicas e instituciones especializadas y dedicadas al tratamiento y la investigación sobre el período o, incluso, en la cantidad comparativamente menor de tesis, estudios, libros o proyectos-. Reflexionar desde aquí quizás puede contribuir no sólo a desnaturalizar la construcción nacional, sino que también a poner en evidencia las tensiones creadoras que han surgido de nuestro pasado colonial, y que han permeado y configurado una forma distinta de situarse y pensar la modernidad americana.

\section{OBRAS CITADAS}

Anderson, Benedict. 2000. Comunidades imaginadas. Reflexiones sobre el origen y difusión del nacionalismo. Buenos Aires: Fondo de Cultura Económica.

Catalán, Gonzalo. 1985. "Antecedentes sobre la transformación del campo literario en Chile entre 1890 y 1920”. En Brunner, José Joaquín y Gonzalo Catalán (Eds.), Cinco estudios sobre cultura y sociedad. Santiago: FLACSO. 69-175.

Chartier, Roger. 2005. El mundo como representación. Estudios sobre historia cultural. Barcelona: Gedisa.

Foucault, Michel. 1999. El orden del discurso. Barcelona: Tusquets.

Hale, Charles. 1990. "Ideas políticas y sociales en América Latina, 1870-1930". En Bethell, Leslie (Comp.), Historia de América Latina. Volumen 8: Cultura y sociedad, 1830-1930. Barcelona: Crítica. 1-64.

Horkheimer, Max y Theodor Adorno. 1998. Dialéctica de la Ilustración. Fragmentos filosóficos. Madrid: Trotta.

Larraín, Jorge. 1996. Modernidad, razón e identidad en América Latina. Santiago: Editorial Andrés Bello.

Lastarria, José Victorino. 1906. "Investigaciones sobre la influencia social de la conquista i del sistema colonial de los españoles en Chile". Obras completas, Volumen 1-2. Estudios políticos i constitucionales. Santiago: Encuadernación Barcelona. Recuperado en mayo de 2015, de http://www.memoriachilena.cl/602/w3-article-8207.html

1973. Don Guillermo. Santiago: Nascimento. Recuperado en mayo de 2015, de www. memoriachilena.cl/archivos2/pdfs/MC0056407.pdf

Meléndez, Mariselle. 1998. "Miedo, raza y nación: Bello, Lastarria y la revisión del pasado colonial". Revista Chilena de Literatura 52: 17-30.

Pratt, Mary Louise. 1997. Ojos imperiales. Buenos Aires: Universidad Nacional de Quilmes.

Subercaseaux, Bernardo. 1997. Historia de las ideas y de la cultura en Chile. Tomo I. "Sociedad y cultura liberal en el siglo XIX: J. V. Lastarria”. Santiago: Universitaria.

2003. "Pensamiento operante y escenificación del tiempo histórico". En Cavieres, Eduardo (Ed.), Entre discursos y prácticas. América Latina en el siglo XIX. Valparaíso: Ediciones Pontificia Universidad Católica de Valparaíso. 47-70.

8 Por colonialidad aludimos al pensamiento crítico respecto de las matrices eurocéntricas bajo las cuales se ha comprendido la relación América-Europa. Ello nos permite estudiar la construcción de sujetos, espacios y saberes desde una lectura que enfatiza en lo distintivo y propio que surge de esta relación con la metrópolis. 
